\title{
Targeted next-generation sequencing identification of mutations in patients with disorders of sex development
}

\author{
Yanling Dong ${ }^{1 \dagger}$, Yuting $\mathrm{Yi}^{2,3,4+}{ }^{2}$ Hong Yao ${ }^{1}$, Ziying Yang ${ }^{2}$, Huamei $\mathrm{Hu}^{1}$, Jiucheng $\mathrm{Liu}^{2}$, Changxin $\mathrm{GaO}^{2}$, \\ Ming Zhang ${ }^{2}$, Liying Zhou ${ }^{2}$, Asan $^{2,3,4}$, Xin $\mathrm{Yi}^{3^{*}}$ and Zhiqing Liang ${ }^{1 *}$
}

\begin{abstract}
Background: The identification of causative mutations is important for treatment decisions and genetic counseling of patients with disorders of sex development (DSD). Here, we designed a new assay based on targeted nextgeneration sequencing (NGS) to diagnose these genetically heterogeneous disorders.

Methods: All coding regions and flanking sequences of 219 genes implicated in DSD were designed to be included on a panel. A total of 45 samples were used for sex chromosome dosage validation by targeted sequencing using the NGS platform. Among these, 21 samples were processed to find the causative mutation.

Results: The sex chromosome dosages of all 45 samples in this assay were concordant with their corresponding karyotyping results. Among the 21 DSD patients, a total of 11 mutations in SRY, NROB1, AR, CYP17A1, GK, CHD7, and SRD5A2 were identified, including five single nucleotide variants, three InDels, one in-frame duplication, one SRYpositive 46,XX, and one gross duplication with an estimated size of more than 427,038 bp containing NROB1 and GK. We also identified six novel mutations: c.230_231insA in SRY, c.7389delA in CHD7, c.273C>G in NROB1, and c.2158G>A, c.1825A>G, and c.2057_2065dupTGTGTGCTG in AR.

Conclusions: Our assay was able to make a genetic diagnosis for eight DSD patients (38.1\%), and identified variants of uncertain clinical significance in the other three cases (14.3\%). Targeted NGS is therefore a comprehensive and efficient method to diagnose DSD. This work also expands the pathogenic mutation spectrum of DSD.
\end{abstract}

Keywords: Disorders of sex development, Targeted next-generation sequencing, Novel mutation

\section{Background}

Disorders of sex development (DSD) are a group of rare conditions involving atypical chromosomal, gonadal, or anatomical sex development. The prevalence of DSD has been estimated to be about 1/4500 live births [1]. According to karyotype, DSD can be classified into sex chromosome DSD, 46,XX DSD, and 46,XY DSD [2], and correct classification is critical for gender assignment, genital surgery, and lifelong care [3]. Thus, accurate genetic testing and the understanding of genotype-phenotype correlations will help refine the diagnosis and management of DSD.

\footnotetext{
*Correspondence: yix@genomics.cn; zhi.Izliang@gmail.com

${ }^{\dagger}$ Equal contributors

${ }^{3}$ BGI-Shenzhen, Shenzhen, China

'Department of Obstetrics \& Gynecology, Southwest Hospital, Third Military Medical University, Chongqing, China

Full list of author information is available at the end of the article
}

The genetic causes of DSD are heterogeneous [4], with more than 60 genes reported to associate with sex determination (gonadal dysgenesis, testicular and ovotesticular DSD), sex differentiation (e.g., steroid synthesis/receptors), and hypogonadism $[5,6]$. Moreover, the genetic changes that occur in DSD are highly complex, including single nucleotide variants (SNVs), small insertions and deletions (InDels), copy number variations (CNVs), $S R Y$-positivity in XX individuals, and sex chromosome abnormalities.

Current genetic testing using Sanger sequencing of candidate genes is both inefficient and time-consuming. Using this method, only $20 \%$ of DSD cases can be diagnosed, leaving most cases of gonadal dysgenesis undiagnosed at the genetic level [5]. In contrast, next-generation sequencing (NGS) can provide high-throughput, accurate screening of multiple genes and different types 
of mutations in a highly efficient manner. Indeed, NGS has been used to diagnose affected individuals of numerous types of disorders affecting multiple genes [7].

A previous pilot testing for DSD involving 35 known DSD genes associated with sex determination and sex differentiation identified genetic causes in two out of seven patients [8]. This relatively low detection rate represented the small gene set in the panel, so expanding the number of candidate genes to several hundred would potentially improve this. In the present study, we performed the genetic testing of 219 DSD-associated genes in a cohort of DSD patients using targeted NGS to expand the DSD spectrum of pathogenic mutations.

\section{Methods}

\section{Patients and other subjects}

Twenty-one Chinese Han probands with DSD (DSD01DSD21) were included in this study. Their phenotypes and clinical findings are described in Table 1. Two patients had siblings affected with the same phenotypes. All patients were diagnosed based on ESPE/LWPES guidelines [9]. An Asian genome ( $\mathrm{YH})$ was used to assess the detection power of our assay [10]. An additional 21 subjects (C01-C21) were recruited for sex chromosome dosage validation, including 17 unaffected individuals with known karyotypes and four individuals with $47, \mathrm{XXY}$ or $45, \mathrm{XO}$. The study was approved by the Institutional Review Board of BGI, and informed consent was obtained from all patients before blood sampling.

\section{Disease selection and panel design}

The DSD testing panel was designed to contain previously reported clinically associated genes [11], and genes associated with sex determination, sex differentiation, and hypogonadism from the Online Mendelian Inheritance in Man (OMIM) database [12], including a subset of genes for syndromes with sex development in OMIM. An additional set of unique genes with an average $10 \mathrm{Mb}$ intermediate distance on $\mathrm{X}$ and $\mathrm{Y}$ chromosomes were included in the panel to estimate sex chromosome dosage (Additional file 1). Exons and flanking sequences of the above genes were targeted in the primary target regions.

Manufacture of the DSD panel was based on the NimbleGen SeqCap EZ Choice Library (Roche). Primary target regions of HG19 NCBI Build 37.1/GRCh37 were submitted online and preprocessed before probe selection. Regions smaller than $100 \mathrm{bp}$ in size were padded to $100 \mathrm{bp}$ from the center to allow for more probe candidates, and overlapping regions were subsequently merged. Probes were selected according to the manufacturer's standard protocols with preferred close matches of 3 and maximum close matches of 5 to minimize cross-hybridization. A total of 2972 exons, and 1,078,042 bases of 219 genes were captured and sequenced in this study.

\section{Targeted genomic capture and next-generation sequencing}

Targeted genomic capture and NGS was performed as previously described [13]. Between 20 and 30 libraries were pooled and hybridized with one customized DSD panel. The captured products were sequenced using the Hiseq2500 system (Illumina, San Diego, CA), and 0.5 G raw data were obtained for each sample.

\section{Alignment and variant detection}

Raw image analysis, base-calling, and error rate analysis were carried out on local computer clusters using the Off-Line Base caller (Illumina, v1.9.4) with default parameters. Adaptor-contaminated reads were discarded, then reads were separated into samples according to their unique indices. For each sample, low quality reads were removed, and clean reads were mapped to the $\mathrm{Hu}$ man GRCh37/hg19 assembly using Burrows-Wheeler Aligner, v0.6.2-r126 [14]. Variant calling (SNVs and InDels) was conducted using the Genome Analysis Tool kit, v3.2-2 [15].

\section{Sex chromosome dosage, CNVs, and 46,XX SRY positive analysis}

In the GC-bias correction process, the following sequential steps were taken: the GC count was determined using 30-bp sliding windows with 25-bp step sizes. Regions shorter than $30 \mathrm{bp}$ were padded equally from both ends to reach $30 \mathrm{bp}$. Then the GC content and read depth were obtained for each window. Smoothing LOWESS regression was applied to the GC content and depth in each window of all chromosomes for each sample. The average depth of all windows was calculated as a baseline. Then, the GC-bias correction factor was calculated as the LOWESS regression value divided by the baseline. Finally the depth of each window was corrected by the correction factor according to its $\mathrm{GC}$ ratio.

Forty uniquely mapping genes on chromosome $\mathrm{X}$ and six uniquely mapping genes on chromosome $\mathrm{Y}$ were used to analyze sex chromosome dosage based on the mapping files (Fig. 1a). After the GC correction process, two steps were taken: 1) the average depth of the windows of all autosomes (ATO) was calculated as a new baseline, excluding the extreme values; and 2) the mean depth of $\mathrm{X}$ and $\mathrm{Y}$ chromosome windows was normalized to the baseline to generate chrX/chrATO and chrY/chrATO.

CNV examination within the captured regions was similar to sex chromosome dosage analysis. After GCbias correction, the coefficient of the recalibrated depth of each window was calculated and the depth distribution profile was obtained. Subsequently, samples of low quality (mean correlation coefficient of all chromosomes $<0.6$, or more than four chromosomes with correlation coefficient values $<4 / 5$ of the mean value 
Table 1 Phenotypic description and previous clinical findings

\begin{tabular}{|c|c|c|c|c|c|}
\hline SamplelD & External genitalia & Anatomy & Gonads & Additional clinical findings & Other diagnostic tests \\
\hline DSD01 & female & no uterus & $\begin{array}{l}\text { streak gonad on left } \\
\text { side; no gonad on right }\end{array}$ & $\begin{array}{l}\text { primary amenorrhea; } \\
\text { mixed germ cell tumor } \\
\text { on right pelvis; tall stature; } \\
\text { breast tannerlll }\end{array}$ & $\begin{array}{l}\text { 46,XY; elevated } \\
\text { FSH、Testosterone } \\
\text { and LH;normal PRL E2 }\end{array}$ \\
\hline DSD02-1 & female & no uterus & bilateral ovary hypoplasia & $\begin{array}{l}\text { Primary amenorrhea; Bilateral } \\
\text { ovarian yolk sac tumor }\end{array}$ & $\begin{array}{l}\text { 46,XY; Familia;elevated } \\
\text { FSH,Testosterone and } \\
\text { LH;normal PRL E2 }\end{array}$ \\
\hline DSD02-2 & female & no uterus & bila. likely fallopian tube tissue & $\begin{array}{l}\text { primary amenorrhea; serous } \\
\text { cystoma on right gonad; } \\
\text { dysgerminoma on left gonad }\end{array}$ & $\begin{array}{l}\text { 46,XY; Familia;elevated } \\
\text { FSH,Testosterone and } \\
\text { LH;normal PRL E2 }\end{array}$ \\
\hline DSD03 & male & hypospadia & no records & no records & $46, X Y ; S R Y$ negative \\
\hline DSD04 & female & small uterus & normal gonad tissue & $\begin{array}{l}\text { primary amenorrhea; short } \\
\text { stature; Dysplastic ears }\end{array}$ & $46, X X$ \\
\hline DSD05 & male & hypospadia; Genital hypoplasia & $\begin{array}{l}\text { two abdominal testes, normal } \\
\text { testicular tissue }\end{array}$ & no records & $46, X X ; S R Y$ negative \\
\hline DSD06 & female & $\begin{array}{l}\text { no uterus; } 1 / 3 \text { vagina present; } \\
\text { Fallopian tubes present }\end{array}$ & ovary; Fallopian tube & primary amenorrhea & $\begin{array}{l}46, X X \text {; normal female } \\
\text { hormonal profile }\end{array}$ \\
\hline DSD07 & male & hypospadia & no records & no records & $46, \mathrm{XY} ; \mathrm{aCGH}$ \\
\hline DSD08 & male; micropenis & $\begin{array}{l}\text { Genital hypoplasia; hypospadia; } \\
2 \mathrm{~cm} \text { phallus }\end{array}$ & $\begin{array}{l}\text { two abdominal testes, } \\
\text { normal testicular tissue }\end{array}$ & no records & $46, X X$ \\
\hline DSD09-1 & male; micropenis & $\begin{array}{l}\text { Genital hypoplasia; hypospadia; } \\
1.8 \mathrm{cmphallus,} \mathrm{small} \mathrm{scrotum}\end{array}$ & normal testicular tissue & no records & 46,XY; Familia \\
\hline DSD09-2 & male & Genital hypoplasia; hypospadia & normal testicular tissue & no records & 46,XY; Familia \\
\hline DSD10 & male & Genital hypoplasia; cavernosa & $\begin{array}{l}\text { no testes tissue;likely } \\
\text { uterus tissue on pelvis }\end{array}$ & no records & $46, X X ; S R Y$ negative \\
\hline DSD11 & male; micropenis & $\begin{array}{l}\text { Fallopian tubes and small } \\
\text { uterus; hypospadia; } 1.5 \mathrm{~cm} \\
\text { phallus, small scrotum }\end{array}$ & likely uterus tissue on pelvis & no records & 46,XX; SRY negative \\
\hline DSD12 & female & small uterus & normal gonad tissue & primary amenorrhea & $46, X X$ \\
\hline DSD13 & female & no uterus & bila.streak gonad & primary amenorrhea & $\begin{array}{l}46, \mathrm{XY} \text {; elevated } \\
\text { testosterone }\end{array}$ \\
\hline DSD14 & female & no uterus & ovotestis with Fallopian tube & primary amenorrhea & $\begin{array}{l}\text { 46,XY; elevated } \\
\text { testosterone; FISH }\end{array}$ \\
\hline DSD15 & $\begin{array}{l}\text { ambiguous } \\
\text { (raised female) }\end{array}$ & small uterus, Genital hypoplasia & $\begin{array}{l}\text { streak gonad on right } \\
\text { side; no gonad on left }\end{array}$ & primary amenorrhea; & $\begin{array}{l}\text { 46,XY; deceased } \\
\text { E2;elevated FSH }\end{array}$ \\
\hline DSD16 & female (clitorism) & no uterus & none found by ultrasound & primary amenorrhea & $\begin{array}{l}\text { 46,XY; elevated } \\
\text { testosterone; FISH }\end{array}$ \\
\hline DSD17 & female & no uterus & none found by ultrasound & primary amenorrhea & $46, X Y$ \\
\hline DSD18 & $\begin{array}{l}\text { female (labia } \\
\text { minora } \\
\text { hypertrophy) }\end{array}$ & no uterus; blind vagina & Partial gonadal dysgenesis & primary amenorrhea & $\begin{array}{l}46, \mathrm{XY} \text {; elevated } \\
\text { testosterone; FISH }\end{array}$ \\
\hline DSD19 & male & Genital hypoplasia; hypospadia & $\begin{array}{l}\text { no uterus;no ovary; } \\
\text { two abdominal testes; } \\
\text { normal testicular tissue }\end{array}$ & no records & $\begin{array}{l}46, X X ; \text { SRY negative; } \\
\text { decreased E2, P, PRL, } \\
\text { FISH; no testosterone }\end{array}$ \\
\hline DSD20 & female (clitorism) & no uterus & none found by ultrasound & primary amenorrhea & $\begin{array}{l}\text { 46,XY; elevated } \\
\text { testosterone; FISH; LH }\end{array}$ \\
\hline DSD21 & $\begin{array}{l}\text { ambiguous } \\
\text { (raised female) }\end{array}$ & no uterus, ovary & none found by ultrasound & primary amenorrhea & $46, X Y$ \\
\hline
\end{tabular}

of other samples) were excluded from further analysis. Batch calibration was performed on the GC-calibrated depth of each window by negative binomial distribution fitting. Then, the hidden Markov model was implemented to estimate the copy number of each window. Regions with more than five continuous supporting windows were selected as CNV candidates.

To avoid the impact of homologous regions between sex chromosomes, samples identified as XX were realigned to the chrY-free reference sequence prior to 


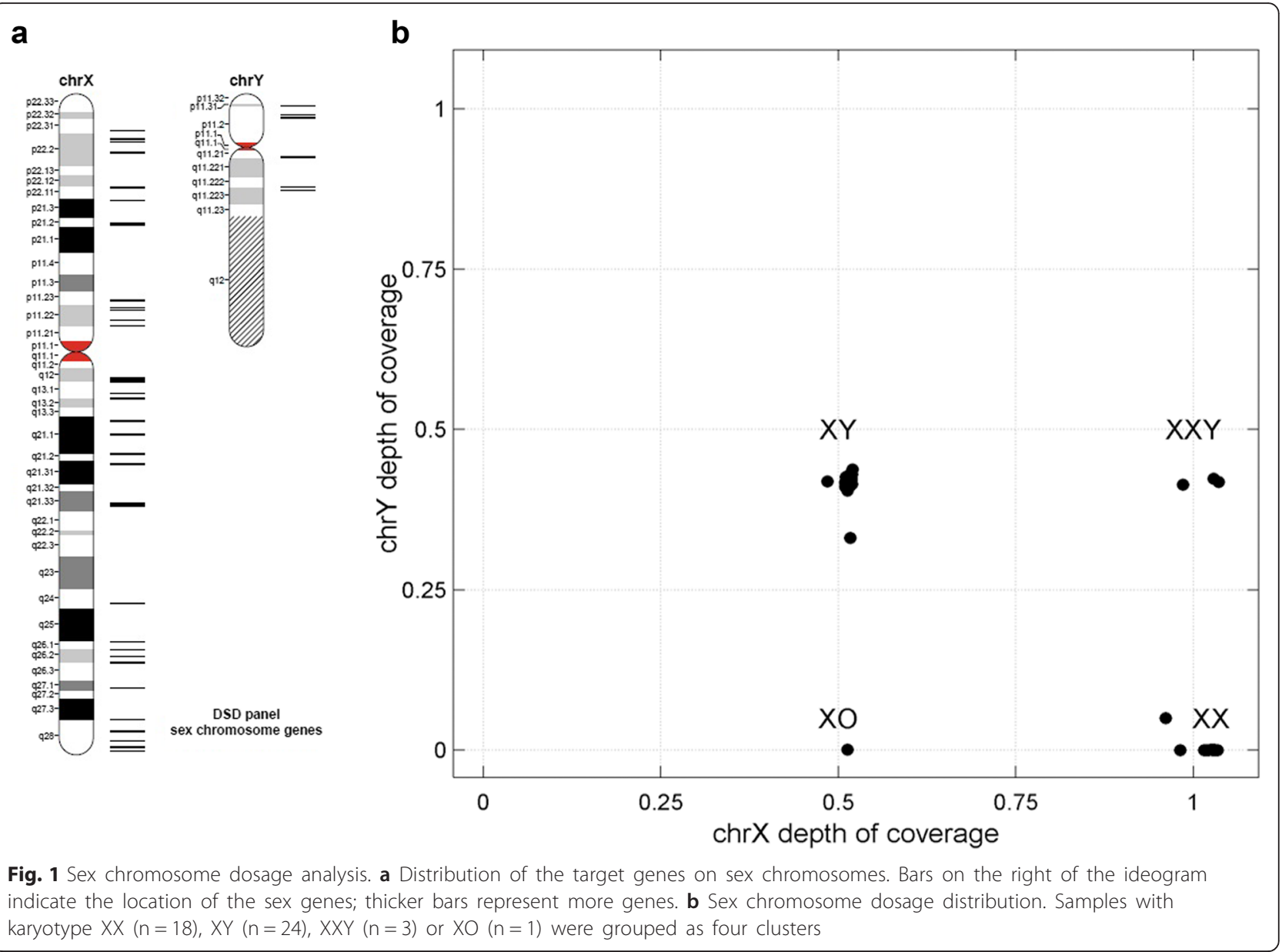

variant calling. To detect $S R Y$-positive variants in $46, \mathrm{XX}$ DSD patients, unmapped pair-end reads were extracted and mapped to the reference sequence of chrY. Sequence depth and coverage of $S R Y$ was determined from the final mapping file.

\section{Confirmation of candidate variants}

Each variant identified by NGS was verified by another method in the patient and available family members. In brief, SNVs and small InDels were confirmed by Sanger sequencing; $\mathrm{CNVs}$ were confirmed by quantitative polymerase chain reaction (qPCR); and 46,XX with $S R Y$ positivity by a PCR assay. Additionally, the possible outcome of non-synonymous SNVs was evaluated by the CONsensus DELeteriousness score (Condel) that combines SIFT and Polyphen2 $[16,17]$ with a conservation score of phyloP.

\section{Results}

\section{Evaluation of quality metrics}

To validate the performance of the NGS panel (including the data analysis pipeline), we assessed key quality metrics using the $\mathrm{YH}$ genome as reference material. As described previously [18], we found that a sequence depth of $>200 \times$ provided a genotype calling sensitivity of $98.73 \%$ ( $>50 \times$ depth) with an accuracy rate of $99.43 \%$ (Additional file 2). We also observed high reproducibility between experiments (Additional file 3). Sensitivity, specificity, and accuracy were all $>99.50 \%$ for SNV calling compared with the published genotyping data for targeted regions (Additional file 3). These results demonstrate the reliability of the experimental approach as well as the data analysis pipeline of the NGS panel.

After aligning reads to the reference human genome, the average sequencing depth for the other 44 samples on the targeted regions was $359 \pm 81 \times$, while $98.06 \%$ of targeted regions were covered by 20 or more reads, indicating the high quality of the data (Additional file 4).

\section{Validation of sex chromosome dosage}

In routine clinical practice, karyotype analysis is necessary for DSD diagnosis, which is essential for understanding the clinical significance of the detected variants. We used 45 samples to assess the detection reliability of sex chromosome dosage in our assay, including 17 with $\mathrm{XX}$ karyotypes, 24 with $\mathrm{XY}$, three with $\mathrm{XXY}$, and one with 
$\mathrm{XO}$. For this purpose, the normalized depths for chromosomes $\mathrm{X}$ and $\mathrm{Y}$ (chrX/chrATO, chrY/chrATO) were calculated and independently examined for each sample. The mean normalized coverage was $0.5134 \pm 0.0068$ for one copy of chrX, $1.0188 \pm 0.0186$ for two copies of chrX, $0.4160 \pm 0.0186$ for one copy of chrY, and $0.0031 \pm 0.0114$ for null chrY (Fig. 1b, Additional file 5). Thus, samples with karyotypes of $\mathrm{XX}, \mathrm{XY}, \mathrm{XXY}$, or $\mathrm{XO}$ were grouped as four clusters. The sex chromosome dosages of all 45 samples were consistent with karyotyping results.

\section{Mutation detection and analysis}

To identify the DSD-causative mutation in each patient, we selected rare SNVs or InDels by four steps of filtering: 1) basic filtering: variants with insufficient sequence coverage (sequencing depth $<8 \times$ coverage and Phred-like quality score $<30$ were ruled out; 2 ) frequency filtering: SNVs or InDels with allelic frequencies $>0.05$ in the 1000 Genomes Project dataset [19] and proprietary exome sequencing dataset were excluded; 3) function region filtering: variants in the intron or untranslated region were discarded, with the exception of splice site mutations or variants recorded in the Human Gene Mutation Database; and 4) clinical phenotype filtering: pedigree co-segregation of disease phenotypes were considered to confirm the causality of the DSD variant.

Among the 21 DSD probands, 11 likely causative mutations in seven genes were identified in 11 patients (52.4\%), including 6/21 (28.6\%) with reported pathogenic findings, $2 / 21$ (9.5 \%) with likely pathogenic findings, and 3/21 (14.3\%) with variants of unknown clinical significance (VUS) according to American College of Medical Genetics and Genomics guidelines for the interpretation of sequence variants [20]. According to the proposed classification of DSD causes, we made a molecular genetic diagnosis for nine of 13 (69.2\%) 46,XY DSD patients, and two of eight (25\%) 46,XX patients.
Among the 11 mutations, a duplication including NROB1 and GK (approximately ChrX:30322539-30749577), c.297 $+2 \mathrm{~T}>\mathrm{C}$ in CYP17A1, and c.2359C $>\mathrm{T}$ (p.Arg787*) and c.174_175insTAG (p.Gln59*) in $A R$ have previously been associated with 46,XY DSD. Moreover, this NGS method detected $S R Y$-positivity in a 46,XX testicular DSD patient, which was subsequently confirmed by PCR assay (Fig. 2).

We also identified six novel candidate mutations in six patients. A hemizygous c.230_231insA mutation in SRY was identified in a female patient with $46, \mathrm{XY}$ complete gonadal dysgenesis (DSD01), and a heterozygous c.7389delA mutation in $C H D 7$ was found in a woman with a small uterus, primary amenorrhea, short stature, and dysplastic ears (DSD04). Both mutations were de novo and were predicted to significantly truncate the coded proteins (Table 2). Additionally, a hemizygous c.273C $>$ G (p.Tyr91*) mutation in NROB1 was detected in a 46,XY male with hypospadias (DSD07), which was similar to a previously reported change in the same nucleotide from $\mathrm{C}$ to A leading to an identical amino acid change (p.Tyr91*) [21]. The remaining two missense variants and one in-frame duplication in $A R$ were c.2158G $>$ A (p.Ala720Thr), c.1825A >G (p.Arg609Gly), and c.2057_2065dupTGTGTGCTG (p.Val686_Ala688dup), respectively. The two missense mutations were predicted to change conserved sites by PhyloP and show deleterious effects by Condel. The c.2158G $>$ A AR mutation was detected in two brothers (DSD09-1, DSD09-2), and had been inherited from their mother. None of these six mutations were found in the 1000 Genomes Project dataset or the in-house database consisting of 1092 Chinese Han normal controls, so were highly likely to be causative of disease (Table 2). All mutations were validated by Sanger sequencing or qPCR (Fig. 3, Additional files 6 and 7).

Multiple variants were identified in 10 additional patients, but none showed consistency with the phenotype or the inheritance of the patients (Additional file 8). In

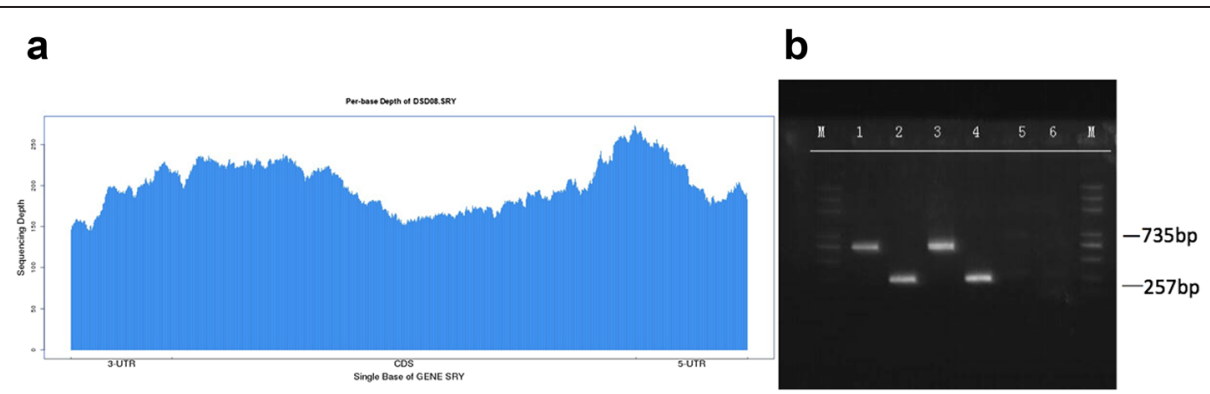

Fig. 2 46,XX SRY-positive was identified in DSD08 in this assay. a The entire SRY gene was covered with a depth of more than 100X in the 46,XX sample through targeted NGS testing. $\mathbf{b}$ NGS results were confirmed by PCR assay. Two primers were designed for this test, one covered the whole SRY gene with a product of $735 \mathrm{bp}$, while the other covered the first $200 \mathrm{bp}$ with a product of $257 \mathrm{bp}$. Lanes 1 and 2: subjects; lanes 3 and 4: SRY-normal samples; lanes 5 and 6: SRY-negative samples 
Table 2 Deleterious variant identification in DSD patients

\begin{tabular}{|c|c|c|c|c|c|c|c|c|c|c|c|}
\hline Sample & Gene & Transcript & Nucleotide change & Protein change & Zygosity & Novel & $M A D^{a} / R^{b}$ & Condel & phyloP & Origin & Interpretation \\
\hline \multicolumn{12}{|c|}{ (1) Mutations identified in $46, X Y$ DSD cases } \\
\hline DSD01 & SRY & NM_003140.1 & c.230_231insA & p.Lys $77 f s^{*} 27$ & Hem & novel & $127 / 1$ & . & & de novo & Likely pathogenic \\
\hline DSD07 & NROB 1 & NM_000475.4 & c. $273 C>G$ & p.Tyr91* & Hem & novel & $68 / 0.83$ & . & . & mat & Pathogenic \\
\hline DSD09-1 & $A R$ & NM_000044.3 & c. $2158 \mathrm{G}>\mathrm{A}$ & p.Ala720Thr & Hem & novel & $154 / 1$ & $D^{c}$ & 5.094 & mat & VUS $^{e}$ \\
\hline DSD09-2 & $A R$ & NM_000044.3 & c. $2158 \mathrm{G}>\mathrm{A}$ & p.Ala720Thr & Hem & novel & $131 / 0.98$ & $\mathrm{D}$ & 5.094 & mat & VUS \\
\hline DSD13 & CYP17A1 & NM_000102.3 & $c .297+2 T>C$ & $\cdot$ & Hom & reported [28] & 189/0.99 & . & & $N D^{d}$ & Pathogenic \\
\hline DSD14 & $A R$ & NM_000044.3 & C. $2359 C>T$ & p.Arg787* & Hem & reported [29] & $142 / 0.99$ & & . & ND & Pathogenic \\
\hline DSD15 & NROB1;GK & NM_000475.4; NM_000167.5 & $\begin{array}{l}\text { Duplication containing Chr X: } \\
\text { 30322539-30749577 }\end{array}$ & . & Het & reported $[25,26]$ & . & . & . & ND & Pathogenic \\
\hline DSD17 & $A R$ & NM_000044.3 & c.174_175insTAGCAGCAGCAGCAG & p.Gln59* & Hem & reported [30] & $49 / 0.96$ & & & mat & Pathogenic \\
\hline DSD18 & $A R$ & NM_000044.3 & c. $1825 A>G$ & p.Arg609Gly & Hem & novel & $126 / 1$ & $\mathrm{D}$ & 1.333 & mat & VUS \\
\hline DSD20 & $A R$ & NM_000044.3 & c.2057_2065dupTGTGTGCTG & p.Val686_Ala688dup & Hem & novel & $110 / 0.98$ & . & & mat & VUS \\
\hline \multicolumn{12}{|c|}{ (2) Mutations identified in $46, X X$ DSD cases } \\
\hline DSD04 & CHD7 & NM_017780.3 & c.7389delA & p.K2464Sfs*39 & Het & novel & $138 / 0.5$ & . & & de novo & Likely pathogenic \\
\hline DSD08 & SRY & NM_003140.1 & . & Positive & Hem & reported [31] & . & . & & de novo & Pathogenic \\
\hline \multicolumn{12}{|c|}{ (3) Only one Mutation identified } \\
\hline DSD02-1 & SRD5A2 & NM_000348.3 & c.737G $>A$ & p.Arg246Gln & Het & reported [32] & $70 / 0.48$ & . & & mat & Pathogenic \\
\hline DSD21 & SRD5A2 & NM_000348.3 & c. $680 \mathrm{G}>\mathrm{A}$ & p.Arg227Gln & Het & reported [33] & $102 / 0.43$ & . & & mat & Pathogenic \\
\hline
\end{tabular}

${ }^{a}$ minor allele depth; ${ }^{b}$ ratio of minor allele depth to total allele depth; ${ }^{c}$ deleterious; ${ }^{d}$ not determined; ${ }^{e}$ variant of unknown significance 


\section{a}



b

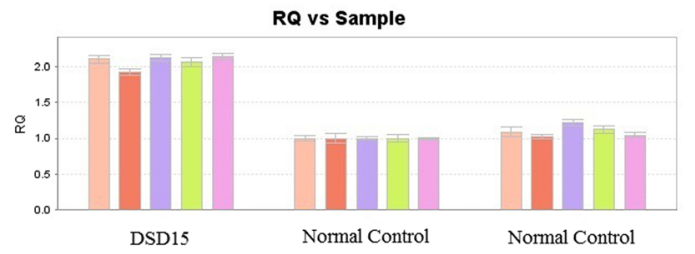

Sample



Fig. 3 A Duplication involving NROB1 and GK was identified in patient DSD15 with 46,XY DSD. a CNV analysis of the subject. Blue spots represent the normal chromosome region with one copy, red spots represent the 207 abnormal bins with two copies. b qPCR validation. The quantity of NROB 1 and GK in the subject is comparable to the normal control

these cases, disorders might be caused by other genetic factors that remain to be discovered.

\section{Discussion}

In this study, we developed a customized panel for testing sex chromosome dosage changes and mutations of DSD genes using NGS-based targeted sequencing technology. Sex chromosome status is crucial for the clinical and molecular diagnosis of DSD because dosage changes of sex chromosomes are accountable for about $20 \%$ of DSD [5] and are important in the interpretation of other types of DSD. Moreover, 46,XY DSD and 46,XX DSD inheritance is complicated because it can be caused by the same gene but result in opposite effects (function gain versus loss). In this study, all 45 patients tested by our assay showed sex chromosome dosage consistent with karyotyping results. Therefore, our assay is capable of distinguishing normal $\mathrm{XX}$ or $\mathrm{XY}$, copy number gain, or loss of sex chromosomes.

Among the 21 patients with an unclear genetic diagnosis, we identified causative mutations in nine of 13 families with 46,XY DSD, and two of eight families with 46,XX DSD. A previous study using whole exome sequencing to diagnose 46,XY DSD identified genetic causes in $35 \%(14 / 40)$ of cases, as well as six VUS variants (15\%) [8]. Thus, our assay outperforms other studies, and is consistent with exome sequencing in the diagnosis of these conditions because of the comprehensive collection of DSD-associated genes included in the panel. Unfortunately, the mutations identified in our study were limited to several common DSD genes as a result of the small sample size.

We identified six novel mutations, which expands our understanding of the mutation spectrum of DSD. A novel deletion in CHD7 was detected in DSD04, in addition to the identification of a frame-shift mutation in $S R Y$ and a nonsense mutation in NROB1. Autosomal dominant inheritance of truncated mutations in $\mathrm{CHD7}$ have been known to cause CHARGE syndrome [22], which is difficult to diagnose from phenotypes because of the high heterogeneity with other conditions. In the case of DSD04, the phenotype resembles that of CHARGE syndrome, so it is very likely that the novel deletion in CHD7 is the causative mutation. In another patient, we found three previously unreported variants, p.Ala720Thr, p.Arg609Gly, and p.Val686_Ala688dup, in the DNA binding and ligand binding domains of $A R$ that are likely to be causative of DSD. Variants in $A R$ are known causes of androgen insensitivity syndrome (AIS) [23]. Over 500 different $A R$ mutations, localized mainly in regions encoding DNA binding (AA:558-624) and ligand binding domains (AA:672-920) [23, 24], from more than 850 patients with AIS have been recorded in the Androgen Receptor Gene Mutations Database.

In patient DSD15 with ambiguous external genitalia, a small uterus, streak gonads on the right hand side and no gonads on the left, and primary amenorrhea, we found a gross duplication estimated to exceed 427,038 bp and involving NROB1, CXorf21, and GK, although only 4517 bp was captured in the assay (Fig. 3a). NROB1 is considered to be an anti-testis gene responsible for gonadal dysgenesis, and loss-of-function mutations in this gene are accountable for congenital adrenal hypoplasia and hypogonadotropic hypogonadism. In contrast, a duplication including a $160-\mathrm{kb}$ minimal common region containing $M A G E B$ and NROB1 can cause sex reversal [25-27]. The smallest CNV segment identified by our assay was $\sim 130 \mathrm{bp}$, suggesting that CNVs less than $130 \mathrm{bp}$ in length could be missed. However, exons $<130$ bp can be identified by manually comparing the exon sequencing depth with other samples in the same batch. And the other CNVs with both less than $130 \mathrm{bp}$ and uncovering an exon is likely to be missed. Another limitation of our analysis is that the precise breakpoint 
of CNVs cannot be precisely determined by our assay, and could be anywhere between the terminal base within the $\mathrm{CNV}$ and the adjacent base in the non-CNV.

\section{Conclusions}

In summary, our findings show that testing a panel of genes associated with DSD can achieve a precise clinical diagnosis of the disease for phenotypically or genetically heterogeneous DSD. Our approach made a clear genetic diagnosis in eight patients $(38.1 \%)$ and identified VUS in the three other cases (14.3\%). NGS-based targeted sequencing using our assay is therefore a promising technique to improve the detection rate of DSD, which would assist clinicians in differential diagnosis, genetic counseling, and timely treatment for affected individuals.

\section{Additional files}

Additional file 1: Genes associated with disorders of sex development (DSD). (XLSX $25 \mathrm{~kb}$ )

Additional file 2: Quality metrics generated using $\mathrm{YH}$ genome sequencing data. (DOC $18.4 \mathrm{~kb}$ )

Additional file 3: SNV validation of the YH sample. (XLSX $12.8 \mathrm{~kb}$ )

Additional file 4: Sequencing quality statistics of all samples.

(XLSX $14.4 \mathrm{~kb})$

Additional file 5: Sex chromosome dosage analysis. (XLSX $14.1 \mathrm{~kb}$ )

Additional file 6: Primers used for candidate variant validation.

(XLSX $17.1 \mathrm{~kb}$ )

Additional file 7: Sanger sequencing of candidate SNVs and Indels. (DOC $417 \mathrm{~kb}$ )

Additional file 8: Number of candidate variants in 23 patients after filtering. (XLSX $13.9 \mathrm{~kb}$ )

\section{Abbreviations}

CNV: copy number variation; DSD: disorders of sex development; Indels: small insertion and deletions; NGS: next-generation sequencing; OMIM: Online Mendelian Inheritance in Man; SNV: single nucleotide variant.

\section{Competing interests}

The authors declare that they have no competing interests.

\section{Authors' contributions}

$Z L, X Y, Y D$, and $Y Y$ conceived and designed the experiments. $Y D, H Y$, and $\mathrm{HH}$ recruited the probands and collected the blood samples. YY, ZY, CG, LZ, and $M Z$ performed targeted NGS screening and bioinformatics analyses. YD and $Y Y$ wrote the manuscript. $J$ and Asan helped to draft the manuscript. All authors read and approved the final manuscript.

\section{Acknowledgments}

The authors thank Dr. Yong Chen and Gongli Chen for the evaluation and diagnosis of patients, and thank all blood donors for their contribution to this study. This work was supported by a grant from the Tianjin Municipal Science and Technology Special Funds for Enterprise Development (No. 14ZXLJSY00320).

\section{Author details}

${ }^{1}$ Department of Obstetrics \& Gynecology, Southwest Hospital, Third Military Medical University, Chongqing, China. ${ }^{2}$ Binhai Genomics Institute, BGI-Tianjin, Tianjin, China. ${ }^{3} \mathrm{BG}-$ Shenzhen, Shenzhen, China. ${ }^{4}$ Tianjin Enterprise Key Laboratory of Clinical Molecular Diagnostic, Tianjin, China.
Received: 1 August 2015 Accepted: 5 March 2016

Published online: 15 March 2016

References

1. Hughes IA, Houk C, Ahmed SF, Lee PA, Lawson Wilkins Pediatric Endocrine Society/European Society for Paediatric Endocrinology Consensus G. Consensus statement on management of intersex disorders. J Pediatr Urol. 2006;2(3):148-62.

2. Erdogan S, Kara C, Ucakturk A, Aydin M. Etiological classification and clinical assessment of children and adolescents with disorders of sex development. J Clin Res Pediatr Endocrinol. 2011:3(2):77-83.

3. Stein MT, Sandberg DE, Mazur T, Eugster E, Daaboul J. A newborn infant with a disorder of sexual differentiation. J Dev Behav Pediatr. 2003:24(2):115-9.

4. Mendonca BB, Domenice S, Arnhold IJ, Costa EM. 46, XY disorders of sex development (DSD). Clin Endocrinol (Oxf). 2009;70(2):173-87.

5. Ono M, Harley VR. Disorders of sex development: new genes, new concepts. Nat Rev Endocrinol. 2013;9(2):79-91.

6. Baxter RM, Arboleda VA, Lee H, Barseghyan H, Adam MP, Fechner PY, Bargman R, Keegan C, Travers S, Schelley S, et al. Exome Sequencing for the Diagnosis of 46, XY Disorders of Sex Development. J Clin Endocrinol Metab. 2015;100(2):E333-44

7. Yang T, Wei X, Chai Y, Li L, Wu H. Genetic etiology study of the nonsyndromic deafness in Chinese Hans by targeted next-generation sequencing. Orphanet J Rare Dis. 2013:8:85.

8. Arboleda VA, Lee H, Sanchez FJ, Delot EC, Sandberg DE, Grody WW, Nelson SF, Vilain E. Targeted massively parallel sequencing provides comprehensive genetic diagnosis for patients with disorders of sex development. Clin Genet. 2013;83(1):35-43.

9. Hughes IA, Nihoul-Fekete C, Thomas B, Cohen-Kettenis PT. Consequences of the ESPE/LWPES guidelines for diagnosis and treatment of disorders of sex development. Best Pract Res Clin Endocrinol Metab. 2007:21(3):351-65.

10. Wang J, Wang W, Li R, Li Y, Tian G, Goodman L, Fan W, Zhang J, Li J, Zhang J, et al. The diploid genome sequence of an Asian individual. Nature. 2008; 456(7218):60-5.

11. Bashamboo A, McElreavey K. Gene mutations associated with anomalies of human gonad formation. Sex Dev. 2013;7(1-3):126-46.

12. Online Mendelian Inheritance in Man. McKusick-Nathans Institute of Genetic Medicine, Johns Hopkins University (Baltimore, MD). 2014. http://omim.org/. Accessed 17 Feb 2014

13. Xie S, Lan Z, Qu N, Wei X, Yu P, Zhu Q, Yang G, Wang J, Shi Q, Wang W. Detection of truncated dystrophin lacking the C-terminal domain in a Chinese pedigree by next-generation sequencing. Gene. 2012;499(1):139-42.

14. Li H, Durbin R. Fast and accurate short read alignment with BurrowsWheeler transform. Bioinformatics. 2009:25(14):1754-60.

15. Van der Auwera GA, Carneiro MO, Hartl C, Poplin R, Del Angel G, LevyMoonshine A, Jordan T, Shakir K, Roazen D, Thibault J, et al. From FastQ data to high confidence variant calls: the Genome Analysis Toolkit best practices pipeline. Curr Protoc Bioinformatics/editoral board, Andreas D Baxevanis [et al]. 2013;11(1110):11.10.11-33.

16. Gonzalez-Perez A, Lopez-Bigas N. Improving the assessment of the outcome of nonsynonymous SNVs with a consensus deleteriousness score, Condel. Am J Hum Genet. 2011;88(4):440-9.

17. Kumar P, Henikoff S, Ng PC. Predicting the effects of coding nonsynonymous variants on protein function using the SIFT algorithm. Nat Protoc. 2009:4(7):1073-81.

18. Martin J, Asan, Yi Y, Alberola T, Rodriguez-Iglesias B, Jimenez-Almazan J, Li Q, Du H, Alama P, Ruiz A, et al. Comprehensive carrier genetic test using next-generation deoxyribonucleic acid sequencing in infertile couples wishing to conceive through assisted reproductive technology. Fertil Steril. 2015;104:1286-93

19. Genomes Project C, Abecasis GR, Auton A, Brooks LD, DePristo MA, Durbin RM, Handsaker RE, Kang HM, Marth GT, McVean GA, et al. An integrated map of genetic variation from 1,092 human genomes. Nature. 2012; 491(7422):56-65.

20. Richards S, Aziz N, Bale S, Bick D, Das S, Gastier-Foster J, Grody WW, Hegde $M$, Lyon E, Spector $E$, et al. Standards and guidelines for the interpretation of sequence variants: a joint consensus recommendation of the American College of Medical Genetics and Genomics and the Association for Molecular Pathology. Genet Med. 2015;17(5):405-24.

21. Guo W, Burris TP, Zhang YH, Huang BL, Mason J, Copeland KC, Kupfer SR, Pagon RA, McCabe ER. Genomic sequence of the DAX1 gene: an orphan 
nuclear receptor responsible for X-linked adrenal hypoplasia congenita and hypogonadotropic hypogonadism. J Clin Endocrinol Metab. 1996;81(7):2481-6.

22. Lalani SR, Safiullah AM, Fernbach SD, Harutyunyan KG, Thaller C, Peterson LE, McPherson JD, Gibbs RA, White LD, Hefner M. Spectrum of CHD7 mutations in 110 individuals with CHARGE syndrome and genotypephenotype correlation. Am J Hum Genet. 2006;78(2):303-14

23. Hughes IA, Davies JD, Bunch TI, Pasterski V, Mastroyannopoulou K, MacDougall J. Androgen insensitivity syndrome. Lancet. 2012;380(9851):1419-28.

24. Gottlieb B, Beitel LK, Nadarajah A, Paliouras M, Trifiro M. The androgen receptor gene mutations database: 2012 update. Hum Mutat. 2012;33(5):887-94.

25. Calvari V, Alpigiani MG, Poggi E, Podesta B, Camerino G, Lorini R. X-linked adrenal hypoplasia congenita and hypogonadotropic hypogonadism: report on new mutation of the DAX-1 gene in two siblings. J Endocrinol Invest. 2006;29(1):41-7.

26. Dabovic B, Zanaria E, Bardoni B, Lisa A, Bordignon C, Russo V, Matessi C, Traversari $C$, Camerino G. A family of rapidly evolving genes from the sex reversal critical region in Xp21. Mamma Genome. 1995;6(9):571-80.

27. Barbaro M, Oscarson M, Schoumans J, Staaf J, Ivarsson SA, Wedell A. Isolated 46, XY gonadal dysgenesis in two sisters caused by a Xp21.2 interstitial duplication containing the DAX1 gene. J Clin Endocrinol Metab. 2007; 92(8):3305-13

28. Hwang DY, Hung CC, Riepe FG, Auchus RJ, Kulle AE, Holterhus PM, Chao MC, Kuo MC, Hwang SJ, Chen HC. CYP17A1 intron mutation causing cryptic splicing in 17alpha-hydroxylase deficiency. PLoS One. 2011;6(9):e25492.

29. Pinsky L, Trifiro M, Kaufman M, Beitel LK, Mhatre A, Kazemi-Esfarjani P, Sabbaghian N, Lumbroso R, Alvarado C, Vasiliou M, et al. Androgen resistance due to mutation of the androgen receptor. Clin Invest Med Medecine clinique et experimentale. 1992;15(5):456-72.

30. Holterhus PM, Werner R, Hoppe U, Bassler J, Korsch E, Ranke MB, Dorr HG, Hiort O. Molecular features and clinical phenotypes in androgen insensitivity syndrome in the absence and presence of androgen receptor gene mutations. J Mol Med. 2005;83(12):1005-13.

31. Margarit E, Coll MD, Oliva R, Gomez D, Soler A, Ballesta F. SRY gene transferred to the long arm of the $\mathrm{X}$ chromosome in a Y-positive $\mathrm{XX}$ true hermaphrodite. Am J Med Genet. 2000;90(1):25-8.

32. Thigpen AE, Davis DL, Milatovich A, Mendonca BB, Imperato-McGinley J, Griffin JE, Francke U, Wilson JD, Russell DW. Molecular genetics of steroid 5 alpha-reductase 2 deficiency. J Clin Invest. 1992;90(3):799-809.

33. Hiort $\mathrm{O}$, Sinnecker $\mathrm{GH}$, Willenbring $\mathrm{H}$, Lehners $\mathrm{A}$, Zollner $\mathrm{A}$, Struve D. Nonisotopic single strand conformation analysis of the 5 alpha-reductase type 2 gene for the diagnosis of 5 alpha-reductase deficiency. J Clin Endocrinol Metab. 1996:81(9):3415-8.

\section{Submit your next manuscript to BioMed Central and we will help you at every step:}

- We accept pre-submission inquiries

- Our selector tool helps you to find the most relevant journal

- We provide round the clock customer support

- Convenient online submission

- Thorough peer review

- Inclusion in PubMed and all major indexing services

- Maximum visibility for your research

Submit your manuscript at wuw biomedcentral.com/submit

CBiomed Central 